\title{
Maturing Myeloid Cell to Total Cell Ratio Measurement
}

National Cancer Institute

\section{Source}

National Cancer Institute. Maturing Myeloid Cell to Total Cell Ratio Measurement. NCI

Thesaurus. Code C127629.

The determination of the ratio of maturing myeloid cells compared to total cells present in a sample. The measurement may be expressed as a ratio or percentage. 